\title{
Characterization of Bioactive Compounds in Tunisian Bitter Orange (Citrus aurantium L.) Peel and Juice and Determination of Their Antioxidant Activities
}

\author{
Iness Jabri karoui and Brahim Marzouk \\ Laboratoire des Substances Bioactives, Centre de Biotechnologie à la Technopole de Borj-Cédria (CBBC), BP 901, \\ 2050 Hammam-lif, Tunisia \\ Correspondence should be addressed to Iness Jabri karoui; iness.karoui@yahoo.fr
}

Received 16 April 2013; Revised 18 May 2013; Accepted 22 May 2013

Academic Editor: Jose R. Botella

Copyright (C) 2013 I. Jabri karoui and B. Marzouk. This is an open access article distributed under the Creative Commons Attribution License, which permits unrestricted use, distribution, and reproduction in any medium, provided the original work is properly cited.

\begin{abstract}
Citrus aurantium peel and juice aroma compounds were investigated by gas chromatography (GC) and gas chromatographymass spectrometry (GC-MS), whereas phenolic compounds analysis was performed by reversed-phase high-performance liquid chromatography (RP-HPLC). Limonene was the major volatile compound of bitter orange peel (90.25\%) and juice (91.61\%). HPLC analysis of bitter orange peel and juice methanolic extracts indicated that phenolic acids constitute their main phenolic class representing $73.80 \%$ and $71.25 \%$, respectively, followed by flavonoids (23.02\% and $23.13 \%$, resp.). $p$-Coumaric and ferulic acids were the most abundant phenolic compounds representing $24.68 \%$ and $23.79 \%$, respectively, in the peel, while the juice contained $18.02 \%$ and $19.04 \%$, respectively. The antioxidant activities of bitter orange peel and juice methanolic extracts have been evaluated using four in vitro assays, and the results were compared with the standard antioxidants (BHT, BHA, and ascorbic acid). Our findings demonstrated that Citrus aurantium peel and juice possess antioxidant activities which were less effective than those of antioxidant standards. Both extracts may be suggested as a new potential source of natural antioxidant.
\end{abstract}

\section{Introduction}

Antioxidants have been widely used as food additives to provide protection against oxidative degradation of foods [1]. The most commonly used synthetic antioxidants are butylated hydroxyanisole (BHA), butylated hydroxytoluene $(\mathrm{BHT})$, Propyl gallate $(\mathrm{PG})$, and butylated hydroquinone. However, these synthetic antioxidants have side effects such as liver damage and carcinogenesis [2]. Therefore, there is a need for isolation and characterization of natural antioxidant having less or no side effects, for use in foods or medicinal materials in order to replace synthetic antioxidants [3]. The importance of aromatic plants as natural antioxidants has been well established $[4,5]$.

The genus Citrus of the family Rutaceae includes several important fruits such as oranges, mandarins, limes, lemons, sour orange, and grapefruits. Citrus fruits are one of the important horticultural crops, with worldwide agricultural production of over 80 million tons per year [6]. Although the fruits are mainly used for dessert, they have important economic value for their essential oils. Citrus essential oils are obtained as byproducts of the Citrus processing and are the most widely used essential oils in the world. In fact, Citrus fruit essential oils and their major components have gained acceptance in the food industry since they have been generally recognized as safe [7]. Citrus essential oils have a wide range of uses. Primarily, they are used as aroma flavour in many food products, including alcoholic and nonalcoholic beverages, marmalades, gelatins, sweets, soft drinks, ice creams, dairy products, oils, candies, and cakes [8-10]. In pharmaceutical industries, they are employed as flavouring agents to mask unpleasant tastes of drugs. Additionally, in perfumery and cosmetics, the low volatile essential oil components play an important role as head notes [8].

In Tunisia, citriculture has existed traditionally, and the Citrus varieties have been naturally selected. The area under 
Citrus cultivation was estimated to be about 19.250 ha with a yearly production of over 230,000 tons. Such high production inevitably satisfies the fresh fruit market, the agrofood industry, and the exportation demands. Sour orange, known as bitter orange, is a well-known Citrus rootstock in Tunisia. Due to its sour and bitter taste, it has not been used as an edible fruit. The juice of the fruit is used in salads for sour taste instead of lemon juice, and the peel is used in jam production [11]. Recently, much attention has been paid to the possible health benefits of dietary phenolics that have antioxidant activities stronger than those of vitamin C. In fact, consumption of Citrus fruit or juice is found to be inversely associated with several diseases [12]. Knekt et al. [13] reported that intake of orange resulted in reducing incidence of asthma in Finland. Citrus fruit extracts are also found to have several inhibitory activities, such as anti-inflammatory, antitumor, antifungal, and blood clot inhibition activities [14]. The health benefits of Citrus fruit have mainly been attributed to the presence of bioactive compounds, such as phenolics (e.g., flavanone glycosides, hydroxycinnamic acids) [15], vitamin C [13], and carotenoids [16]. However, there is hardly any data on the essential oil and phenolics of Tunisian Citrus species. Also, to the best of our knowledge, there has been very limited research into the antioxidant capacities of sour orange peel and juice. Therefore, the aim of this research is to study the bioactive contents of Tunisian Citrus aurantium juice and peel and to evaluate the antioxidant capacity of their extracts.

\section{Materials and Methods}

2.1. Chemicals. All solvents used in the experiments (diethyl ether, chloroform, hexane, acetonitrile, and methanol) were purchased from Merck (Darmstadt, Germany). Sodium methylate $\left(\mathrm{CH}_{3} \mathrm{ONa}\right)$, sodium chloride $(\mathrm{NaCl})$, sulphuric acid $\left(\mathrm{H}_{2} \mathrm{SO}_{4}\right), \beta$-carotene, linoleic acid, butylated hydroxyltoluene (BHT), butylated hydroxyanisole (BHA), ethylenediaminetetraacetic acid (EDTA), gallic acid, 2,2-Diphenyl-1picrylhydrazyl (DPPH), trichloroacetic acid, iron(II)chloride $\left(\mathrm{FeCl}_{2}\right)$, iron(III)chloride anhydrous $\left(\mathrm{FeCl}_{3}\right)$, ascorbic acid, Kaliumhexacyanoferrat(III), and potassium ferricyanide $\left(\mathrm{K}_{3} \mathrm{Fe}(\mathrm{CN})_{6}\right)$ were obtained from Sigma-Aldrich (Steinheim, Germany). Essential oil standards were purchased from Fluka and Sigma-Aldrich (Steinheim, Germany). Homologous series of $\mathrm{C}_{8}-\mathrm{C}_{22} \mathrm{n}$-alkanes used for identification were obtained from Sigma-Aldrich (Steinheim, Germany). Authentic standards of phenolic compounds were purchased from Sigma and Fluka. Stock solutions of these compounds were prepared in HPLC grade methanol. These solutions were wrapped in aluminium foil and stored at $4^{\circ} \mathrm{C}$. All other chemicals used were of analytical grade.

2.2. Plant Material. Bitter orange (Citrus aurantium L.) is a plant that belongs to the Rutaceae family. Its fruit pulp is acidic and the albedo is bitter [17]. Fresh fruits used in our research come from an orchard located at the Cap-Bon region (North-East of Tunisia); they have been harvested from four selected trees, peeled, and pressed, and the peel and juice were used fresh.
2.3. Essential Oil Extraction. Three lots of $100 \mathrm{~g}$ of fresh peel were separately hydrodistilled for $90 \mathrm{~min}$ (time kept constant after a kinetic survey during 30,60, 90, 120, and $150 \mathrm{~min}$ ). The volatile compounds of the oil were collected in diethyl ether using liquid-liquid isolation. All experiments were done in triplicates, and results were expressed in percentages.

Juice aroma was extracted according to the protocol described by Tønder et al. [18]. In order to survey the juice aroma content of Citrus fruits, $30 \mathrm{~g}$ of juice was extracted with $30 \mathrm{~mL}$ of a mixture of ether-pentane: $(1: 1, \mathrm{v}: \mathrm{v})$. A known quantity of 2-undecanone was added as an internal standard. The mixture was extracted under magnetic stirring for $30 \mathrm{~min}$. After standing for $15 \mathrm{~min}$, the sample was frozen at $-20^{\circ} \mathrm{C}$. When the water phase was frozen, the organic phase was recovered in a quickfit pear-shaped flask provided by a Vigreux column then placed in a water bath regulated at $36^{\circ} \mathrm{C}$ until concentration of the sample to a minimum volume of about $100 \mathrm{~mL}$.

2.4. Gas Chromatography-Flame Ionization Detection (GCFID). Peel and juice volatiles were analysed by GC using a Hewlett-Packard 6890 apparatus (Agilent technologies, Palo Alto, CA, USA) equipped with a flame ionization detector (FID) and an electronic pressure control (EPC) injector. A polyethylene glycol capillary column (HP INNOWax, $30 \mathrm{~m}$ $\times 0.25 \mathrm{~mm}$ i.d, $0.25 \mu \mathrm{m}$ film thickness) was used; the flow of the carrier gas $\left(\mathrm{N}_{2}, \mathrm{U}\right)$ was $1.6 \mathrm{~mL} \mathrm{~min}^{-1}$, and the split ratio was $60: 1$. Analyses were performed using the following temperature program: oven temperature isotherm at $35^{\circ} \mathrm{C}$ for $10 \mathrm{~min}$, from 35 to $205^{\circ} \mathrm{C}$ at the rate of $3^{\circ} \mathrm{C} \mathrm{min}{ }^{-1}$, and isotherm at $205^{\circ} \mathrm{C}$ over $10 \mathrm{~min}$. Injector and detector temperatures were held, respectively, at 250 and $300^{\circ} \mathrm{C}$. Surfaces of peaks and percentages of the different compounds were determined using the same HP chemStation cited above.

2.5. Gas Chromatography-Mass Spectrometry (GC-MS). GCMS analyses were carried out on a gas chromatograph, an HP 5890 series (II) coupled to an HP 5972 mass spectrometer (Agilent Technologies, Palo Alto, CA, USA) with electron impact ionization $(70 \mathrm{eV})$. An HP-5MS capillary column $(30 \mathrm{~m} \times 0.25 \mathrm{~mm}, 0.25 \mu \mathrm{m}$ film thickness Agilent Technologies, Hewlett-Packard, CA, USA) was used. Column temperature was programmed to rise from $50^{\circ} \mathrm{C}$ to $240^{\circ} \mathrm{C}$ at a rate of $5^{\circ} \mathrm{C} / \mathrm{min}$. The carrier gas was helium with a flow rate of $1.2 \mathrm{~mL} / \mathrm{min}$ and a split ratio of $60: 1$. Scan time and mass range were $1 \mathrm{~s}$ and $40-300 \mathrm{~m} / z$, respectively.

2.6. Compounds Identification. Volatile components were identified by comparison of their retention indices (RI) relative to $\left(\mathrm{C}_{8}-\mathrm{C}_{22}\right) \mathrm{n}$-alkanes with those of the literature or with those of authentic compounds available in our laboratory. Further identification was made by matching their recorded mass spectra with those stored in the Wiley/NBS mass spectral library of the GC/MS data system and other published mass spectra [19]. Determination of the component percentages was based on peak area normalization without using correction factors. Analyses were performed in triplicate. 
2.7. Polyphenol Extraction. Fresh peels were dipped in liquid nitrogen according to Ghasemi et al. [20] method and ground into a fine powder using a prechilled mortar and pestle. Triplicate subsamples of $1 \mathrm{~g}$ of ground peel were extracted by stirring with $10 \mathrm{~mL}$ of pure methanol for $30 \mathrm{~min}$. The extract was then kept for $24 \mathrm{~h}$ at $4^{\circ} \mathrm{C}$, filtered through a Whatman number 4 filter paper, evaporated under vacuum to dryness, and stored at $4^{\circ} \mathrm{C}$ until analyzed [21]. Extracts obtained will serve for the quantification of polyphenols components and the evaluation of antioxidant activities.

One millilitre of juice was extracted with $9 \mathrm{~mL}$ of $80 \%$ methanol for $30 \mathrm{~min}$ at room temperature according to $\mathrm{Xu}$ et al. [22]. After centrifugation at $3000 \times \mathrm{g}$ for $10 \mathrm{~min}$, the supernatant was taken out for determination of polyphenols components and antioxidant capacity.

\subsection{Reversed-Phase (RP-HPLC) Analysis and Identification of} Phenolic Compounds. For HPLC analysis, $500 \mu \mathrm{L}$ of resorcinol $\left(1 \mathrm{mg} \mathrm{mL}^{-1}\right)$, as internal standard, was added to the methanolic extract. The phenolic compound analysis was carried out using an Agilent Technologies 1100 series liquid chromatograph (RP-HPLC) coupled with a UV-vis multiwavelength detector. The separation was carried out on a $250 \times 4.6 \mathrm{~mm}, 4 \mu \mathrm{m}$ Hypersil ODS C18 reversed phase column at ambient temperature. The mobile phase consisted of acetonitrile (solvent A) and water with $0.2 \%$ sulphuric acid (solvent B). The flow rate was kept at $0.5 \mathrm{~mL} / \mathrm{min}$. The gradient programme was as follows: $15 \% \mathrm{~A} / 85 \% \mathrm{~B} 0$ 12 min, $40 \%$ A $/ 60 \%$ B $12-14 \mathrm{~min}, 60 \%$ A $/ 40 \%$ B $14-18$ min, $80 \% \mathrm{~A} / 20 \%$ B $18-20 \mathrm{~min}, 90 \% \mathrm{~A} / 10 \%$ B $20-24 \mathrm{~min}$, and $100 \%$ A $24-28 \mathrm{~min}$ [23]. The injection volume was $20 \mu \mathrm{L}$, and peaks were monitored at $280 \mathrm{~nm}$. Samples were filtered through a $0.45 \mu \mathrm{m}$ membrane filter before injection. Phenolic compounds were identified according to their retention times as well as by spiking the sample with standards. Analyses were performed in triplicate.

2.9. Total Antioxidant Capacity. The assay is based on the reduction of $\mathrm{Mo}(\mathrm{VI})$ to $\mathrm{Mo}(\mathrm{V})$ by a flower methanolic extract and subsequent formation of a green phosphate/ $\mathrm{Mo}(\mathrm{V})$ complex at acid pH [24]. An aliquot of methanolic extract was combined in an Eppendorf tube with $1 \mathrm{~mL}$ of reagent solution $(0.6 \mathrm{M}$ sulfuric acid, $28 \mathrm{mM}$ sodium phosphate, and $4 \mathrm{mM}$ ammonium molybdate). The tubes were incubated in a thermal block at $95^{\circ} \mathrm{C}$ for $90 \mathrm{~min}$. After the mixture had cooled to room temperature, the absorbance of each solution was measured at $695 \mathrm{~nm}$ (Anthelie Advanced 2, SECOMAN) against a blank solution. The antioxidant capacity was expressed as mg gallic acid equivalents per gram of fresh weight for the peel extract (mg GAE/g of FW) and per liter for the juice extract (mg GAE/L). All samples were analyzed in three replications.

2.10. DPPH Assay. The electron donation ability of the obtained extract was measured by bleaching of the purplecoloured solution of 1,1-diphenyl-2-picrylhydrazyl radical (DPPH) according to the method of Hatano et al. [25]. A total of $1 \mathrm{~mL}$ of different methanolic extracts concentrations $(1,10$,
20 , and $100 \mu \mathrm{g} / \mathrm{mL}$ ) were added to $0.5 \mathrm{~mL}$ of a $0.2 \mathrm{mmol} / \mathrm{L}$ DPPH methanolic solution. The mixture was shaken vigorously and left standing at room temperature for $30 \mathrm{~min}$. The absorbance of the resulting solution was then measured at $517 \mathrm{~nm}$ after $30 \mathrm{~min}$. The antiradical activity (three replicates per treatment) was expressed as $\mathrm{IC}_{50}$ (concentration required to cause a $50 \% \mathrm{DPPH}$ inhibition: $\mu \mathrm{g} / \mathrm{mL}$ ) for the peel extract and as $I \%$ for the juice extract. The ability to scavenge the DPPH radical was calculated using the following equation:

$$
\text { DPPH scavenging effect }(\%)=\left[\frac{\left(A_{0}-A_{1}\right)}{A_{0}}\right] \times 100 \text {, }
$$

where $A_{0}$ is the absorbance of the control at $30 \mathrm{~min}$ and $A_{1}$ is the absorbance of the sample at $30 \mathrm{~min}$. BHT was used as a positive control. All samples were analyzed in triplicate.

2.11. Reducing Power Ability. In this assay, the yellow colour of the test solution changes to green depending on the reducing power of test specimen. The presence of reductants in the solution causes the reduction of the $\mathrm{Fe}^{3+} /$ ferricyanide complex to the ferrous form. Therefore, $\mathrm{Fe}^{2+}$ can be monitored by the measurement of the absorbance at $700 \mathrm{~nm}$ [26]. The method of Oyaizu [27] was used to assess the reducing power of peel and juice extracts. A total of $1 \mathrm{~mL}$ of different extracts concentrations $(20,100,200$, and $500 \mu \mathrm{g} / \mathrm{mL})$ were mixed with $2.5 \mathrm{~mL}$ of a $0.2 \mathrm{M}$ sodium phosphate buffer $(\mathrm{pH}$ 6.6, prepared from $62.5 \mathrm{~mL}$ of a $0.2 \mathrm{M} \mathrm{Na}_{2} \mathrm{HPO}_{4}, 37.5 \mathrm{~mL}$ of $0.2 \mathrm{M} \mathrm{NaH}_{2} \mathrm{PO}_{4} \cdot \mathrm{H}_{2} \mathrm{O}$ ), and $2.5 \mathrm{~mL}$ of $1 \% \mathrm{~K}_{3} \mathrm{Fe}(\mathrm{CN})_{6}$, and incubated in a water bath at $50^{\circ} \mathrm{C}$ for $20 \mathrm{~min}$. Then, $2.5 \mathrm{~mL}$ of $10 \%$ trichloroacetic acid was added to the mixture that was centrifuged at $650 \mathrm{~g}$ for $10 \mathrm{~min}$. The supernatant $(2.5 \mathrm{~mL})$ was then mixed with $2.5 \mathrm{~mL}$ distilled water and $0.5 \mathrm{~mL}$ of $0.1 \%$ ferric chloride solution. The intensity of the blue-green colour was measured at $700 \mathrm{~nm}$. The $\mathrm{EC}_{50}$ value $(\mathrm{mg} / \mathrm{mL})$ is the extract concentration at which the absorbance was 0.5 for the reducing power and was calculated from the graph of absorbance at $700 \mathrm{~nm}$ against extract concentration. Ascorbic acid was used as positive control. Tests were carried out in triplicate.

2.12. $\beta$-Carotene Bleaching Test. A slightly modified Koleva et al. [28] method was employed to estimate sample methanolic extract capacity to inhibit the $\beta$-carotene bleaching. $\beta$ carotene $(2 \mathrm{mg})$ was dissolved in $20 \mathrm{~mL}$ chloroform, and to $4 \mathrm{~mL}$ of this solution, linoleic acid $(40 \mathrm{mg})$ and Tween $40(400 \mathrm{mg})$ were added. Under vacuum at $40^{\circ} \mathrm{C}$, the chloroform was evaporated, and $100 \mathrm{~mL}$ of oxygenated water was added, and then the emulsion was vigorously shaken. Reference compounds (BHT and BHA) and samples extracts were prepared in methanol. An aliquot $(150 \mu \mathrm{L})$ of the $\beta$ carotene/linoleic acid emulsion was distributed in each of the wells of 96-well microtiter plates, and methanolic solutions of the test samples $(10 \mu \mathrm{L})$ were added. Three replicates were prepared for each of the sample concentration. The microtiter plates were incubated at $50^{\circ} \mathrm{C}$ for $120 \mathrm{~min}$, and the absorbance was measured at $470 \mathrm{~nm}$ using a microtiter reader (model EAR 400, Labsystems Multiskan MS). Readings of all samples were performed immediately $(t=0 \mathrm{~min})$ and after $30 \mathrm{~min}$ or 
120 min of incubation. BHT and BHA were used as standard antioxidants. The antioxidant activity (\%) of the peel and juice extracts was evaluated in terms of $\beta$-carotene bleaching inhibition using the following formula:

$$
\% \text { Inhibition }=\left[\frac{\left(A_{t}-C_{t}\right)}{\left(C_{0}-C_{t}\right)}\right] \times 100,
$$

where $A_{t}$ and $C_{t}$ are the absorbance values measured for the test sample and control, respectively, after incubation for $120 \mathrm{~min}$, and $C_{0}$ is the absorbance values for the control measured at zero time during the incubation. The results are expressed as $\mathrm{IC}_{50}$ values (concentration required to cause a $50 \% \beta$-carotene bleaching inhibition: $\mathrm{mg} / \mathrm{mL}$ ) for the peel extract and as $\% I$ for the juice extract. Tests were carried out in triplicate.

2.13. Statistical Analysis. All data were reported as means \pm standard deviation of three samples. Statistical analysis was performed with STATISTICA [29]. Differences were tested for significance by the ANOVA procedure, using a significance level of $P \leq 0.05$.

\section{Results and Discussions}

3.1. Volatile Compounds of Bitter Orange Peel and Juice. Volatile compounds of Citrus aurantium peel and juice, their retention indexes and percentages, were listed in Table 1. All the constituents were arranged in order of their elution on the HP-5 column, although the retention indexes of compounds confirmed on HP INNOWax column have been also included.

Twenty-seven components were identified in the Citrus aurantium peel essential oil, amounting to $99.48 \%$ of the total oil. Peel essential oil was dominated by monoterpene hydrocarbons (93.49\%), and limonene was the major constituent (90.25\%) followed by $\alpha$-terpinene $(1.10 \%)$. Linalool was the main oxygenated monoterpenes (1.56\%) of the essential oil.

Twelve compounds were identified in the juice representing $99.56 \%$ of the total aroma. As with sour orange peel, juice aroma comprised mainly monoterpene hydrocarbons with limonene $(91.61 \%), \alpha$-phellandrene (1.84\%), and $\alpha$ thujene $(1.03 \%)$ being the major components. Among oxygenated sesquiterpenes, the main component was caryophyllene oxide $(1.42 \%)$. Our data were in concordance with the limonene chemotype of Citrus aurantium growing in Tunisia (stage 3: mature), previously reported by Saidani and Marzouk [30], Tounsi et al. [31], and Hosni et al. [32].

Previous compositional studies regarding the peel oil and juice aroma constituents of sour orange showed similar results proving that limonene was the major volatile compound. Indeed, Boussaada and Chemli [33] have reported that the content of limonene in Tunisian sour orange var. Amara varied from $87 \%$ to $92.2 \%$ on fresh weight basis. These values are lower than those obtained herein. Report from Italy has shown that limonene $(94.3 \%)$ followed by myrcene (1.88\%), linalool $(0.78 \%)$, and $\alpha$-pinene $(0.4 \%)$ was the chief components of sour orange [34]. More recently, Moraes et al. [35] have investigated the peel oil composition of Brazilian
Citrus aurantium without specifying the variety and found that limonene (97.5-98\%), myrcene (1.2-1.45\%), and octanol (0.34-0.54\%) were the prominent compounds.

Several investigations have confirmed the limonene importance in Citrus juice [36, 37]. Moufida and Marzouk [30] showed that limonene was the major volatile component of four Citrus species representing 63\% in blood orange and $90 \%$ in sour orange. In addition, Tønder et al. [18], reported that limonene was the most abundant compound in orange juice $(88.9 \%)$ which is in agreement with our results. Tounsi et al. [31] showed that limonene was highly represented in mandarin juice (69.59\%), blood orange (57.65\%), and bitter orange $(48.85 \%)$. This latter value is lower than that obtained herein.

Limonene is one of the most common terpenes in nature and is the major constituent of an essential oil series. Its pleasant citric fragrance is commonly used as a flavoring in foods and drinks [38], for which it is classified in the U.S. Code of Federal Regulation as safe. According to Moraes et al. [35], besides being popular flavoring agents found in common food items, the essential oil from C. aurantium and its major constituent limonene present substantial antiulcerogenic and gastroprotective actions that can be regarded as a promising target for the development of a new drug for the prevention of gastric ulcer. Tests on animals have proven the effectiveness of limonene against some types of cancer including gastric, mammary, pulmonary adenoma, and liver [38]. Besides the effectiveness of limonene in traditional medicine to treat severe dermatitis, fatigue recovery [39], and depression [40], different studies have reported its anxiolytic and antidepressant effects on the central nervous system [41].

3.2. Identification and Quantification of Phenolic Compounds by RP-HPLC. Polyphenol qualitative and quantitative determination of Citrus aurantium peel and juice was performed by RP-HPLC analysis. The chromatogram of bitter orange peel and juice methanolic extracts as compared to authentic standards of phenolic acid, flavonoid, and phenolic monoterpenes profiles (Figure 1) allowed to identify fifteen phenolic compounds including ten phenolic acids (gallic, vanillic, $p$-coumaric, chlorogenic, syringic, rosmarinic, trans2-hydroxycinnamic, ferulic, $p$-coumaric, and trans-cinnamic acids), five flavonoids (gallate epicatechin, catechin, rutin, naringin, and flavone) in the peel extract, nine phenolic acids (gallic, hydroxybenzoic, syringic, vanillic, rosmarinic, trans-2-hydroxycinnamic, trans-cinnamic, and p-coumaric and ferulic), five flavonoids (epicatechin, catechin, rutin, naringin, and flavone), and one phenolic alcohol (tyrosol) in the juice extract (Figure 1). The main phenolic class of the peel and juice extracts (Table 2) was phenolic acids representing $73.8 \%(1.03 \mathrm{mg} / \mathrm{g})$ and $71.25 \%(473.89 \mathrm{mg} / \mathrm{L})$, respectively, followed by flavonoids $(23.02 \% ; 0.33 \mathrm{mg} / \mathrm{g}$ of the peel) and (23.13\%; $136.91 \mathrm{mg} / \mathrm{L}$ of juice). $p$-Coumaric and ferulic acids were the most abundant phenolic compounds of Citrus aurantium representing $24.68 \%$ and $23.79 \%$, respectively, in the peel extract and $18.02 \%$ and $19.04 \%$, respectively, in the juice. Among flavonoids, rutin was the most abundant compound constituting $9.91 \%$ of the peel extract phenols and $5.98 \%$ of the juice. 
TABLE 1: Essential oil composition of Citrus aurantium peel and juice ${ }^{\mathrm{A}}$.

\begin{tabular}{|c|c|c|c|c|c|}
\hline Volatile compounds & $\mathrm{RI}^{\mathrm{a}}$ & $\mathrm{RI}^{\mathrm{b}}$ & Peel & Juice & Identification \\
\hline$\alpha$-thujene & 928 & 1035 & - & $1.03 \pm 0.04^{\mathrm{a}}$ & IR. SM. Co-CG \\
\hline Tricyclen & 930 & 1015 & - & $0.68 \pm 0.18^{\mathrm{a}}$ & IR. Co-CG. SM \\
\hline$\alpha$-Pinene & 939 & 1032 & $0.55 \pm 0.06^{\mathrm{a}}$ & $0.55 \pm 0.01^{\mathrm{a}}$ & IR. Co-CG. SM \\
\hline$\beta$-Pinene & 980 & 1118 & $0.44 \pm 0.04^{\mathrm{a}}$ & - & IR. SM. Co-CG \\
\hline Sabinene & 975 & 1132 & $0.48 \pm 0.16^{\mathrm{a}}$ & - & CG-SM \\
\hline Myrcene & 991 & 1174 & $0.04 \pm 0.00^{\mathrm{b}}$ & $0.68 \pm 0.16^{\mathrm{a}}$ & IR. SM. Co-CG \\
\hline$\alpha$-Phellandrene & 1006 & 1176 & - & $1.84 \pm 0.04^{\mathrm{a}}$ & CG-SM \\
\hline$\alpha$-Terpinene & 1018 & 1188 & $1.10 \pm 0.27^{\mathrm{a}}$ & - & IR. CG-SM \\
\hline Limonene & 1030 & 1203 & $90.25 \pm 0.81^{\mathrm{a}}$ & $91.61 \pm 0.97^{\mathrm{a}}$ & IR. SM. Co-CG \\
\hline 1-8 Cineole & 1033 & 1213 & $0.87 \pm 0.06^{\mathrm{a}}$ & $0.31 \pm 0.04^{\mathrm{b}}$ & IR. SM. Co-CG \\
\hline E- $\beta$-Ocimene & 1050 & 1266 & $0.36 \pm 0.00^{\mathrm{a}}$ & - & IR. CG-SM \\
\hline Terpinolene & 1088 & 1290 & $0.28 \pm 0.01^{\mathrm{a}}$ & - & IR. SM. Co-CG \\
\hline Cis-linalool oxide & 1074 & 1478 & $0.23 \pm 0.03^{\mathrm{a}}$ & $0.49 \pm 0.23^{\mathrm{a}}$ & CG-SM \\
\hline Trans-linalool oxide & 1088 & 1450 & $0.13 \pm 0.01^{\mathrm{b}}$ & $0.21 \pm 0.01^{\mathrm{a}}$ & CG-SM \\
\hline Linalool & 1098 & 1553 & $1.56 \pm 0.08^{\mathrm{a}}$ & - & IR. SM. Co-CG \\
\hline Linalyl acetate & 1257 & 1556 & $0.29 \pm 0.02^{\mathrm{a}}$ & - & IR. SM. Co-CG \\
\hline Bornyl acetate & 1270 & 1590 & $0.14 \pm 0.05^{\mathrm{a}}$ & - & CG-SM \\
\hline Terpinene-4-ol & 1419 & 1612 & $0.06 \pm 0.01^{\mathrm{a}}$ & - & CG-SM \\
\hline$\beta$-Caryophyllene & 1178 & 1611 & $0.05 \pm 0.01^{\mathrm{a}}$ & - & CG-SM \\
\hline$\gamma$-Elemene & 1492 & 1623 & $0.05 \pm 0.00^{\mathrm{a}}$ & - & CG-SM \\
\hline Neral & 1240 & 1694 & $0.13 \pm 0.00^{\mathrm{a}}$ & - & CG-SM \\
\hline$\beta$-Farnesene & 1456 & 1696 & $0.15 \pm 0.15^{\mathrm{a}}$ & - & CG-SM \\
\hline$\alpha$-Terpineol & 1189 & 1709 & $0.56 \pm 0.03^{\mathrm{a}}$ & $0.38 \pm 0.08^{b}$ & IR. SM. Co-CG \\
\hline Neryl acetate & 1385 & 1733 & $0.23 \pm 0.03^{\mathrm{b}}$ & $0.36 \pm 0.06^{\mathrm{a}}$ & IR. SM. Co-CG \\
\hline$\Delta$-Cadinene & 1523 & 1755 & $0.28 \pm 0.02^{\mathrm{a}}$ & - & CG-SM \\
\hline Geranyl acetate & 1383 & 1765 & $0.11 \pm 0.00^{\mathrm{a}}$ & - & IR. SM. Co-CG \\
\hline Nerol & 1228 & 1797 & $0.08 \pm 0.00^{\mathrm{a}}$ & - & CG-SM \\
\hline Geraniol & 1255 & 1857 & $0.16 \pm 0.01^{\mathrm{a}}$ & - & IR. SM. Co-CG \\
\hline E-Nerolidol & 1566 & 2030 & $0.35 \pm 0.04^{\mathrm{a}}$ & - & CG-SM \\
\hline Oxyde de caryophyllène & 1581 & 2008 & - & $1.42 \pm 0.51^{\mathrm{a}}$ & IR. CG-SM \\
\hline E.Z farnesyl acetate & 1818 & 2198 & $0.57 \pm 0.02^{\mathrm{a}}$ & - & CG-SM \\
\hline NI & & & $0.52 \pm 0.03$ & $0.44 \pm 0.05$ & \\
\hline
\end{tabular}

${ }^{\mathrm{A}}$ Values are given as mean $\pm \mathrm{SD}(n=3)$. Values followed by the same letter did not share significant differences at $P<0.05$ (Duncan's test). - : not detected.

${ }^{\mathrm{b}}$ Components are listed in order of elution in apolar column (HP-5).

${ }^{c} \mathrm{RI}^{\mathrm{a}}, \mathrm{RI}^{\mathrm{b}}$ : retention indices calculated using, respectively, an apolar column (HP-5) and polar column (HP INNOWax). Volatile compound proportions were calculated from the chromatograms obtained on the HP INNOWax column.

Bocco et al. [42] reported similar results showing the prevalence of phenolic acids in Citrus fruits. In addition, Robbins [43] found that phenolic acids (caffeic, $p$-coumaric, ferulic, and sinapic) are characteristic of Citrus. Similarly, Gorinstein et al. [44] found that ferulic, sinapic, $p$-coumaric, and caffeic acids amounts were significantly higher in the peel than in the fruit peeled. Generally, the methanol extracts of Citrus peels are known for their richness in phenolic compounds, such as phenolic acids and flavonoids [45]. Moreover, Anagnostopoulou et al. [46] reported that the peel was the richest part in flavonoids of Citrus fruits. Previous studies have also shown the presence of higher contents of phenolic compounds in fruit peel than segment of Citrus [44, 47].
Our results are also comparable to those of Tounsi et al. [31] who confirmed the richness of Citrus juice in phenolic acids, which constitute $86.4 \%$ of the bitter orange juice TP, $73.13 \%$ of the mandarin, $83.90 \%$ of blood orange juice, and $74.52 \%$ of the lemon. These authors found that ferulic (20.42\%), vanillic (19.76\%), rosmarinic (18.7\%), and $p$ coumaric (15.10\%) acids were the major phenolic compounds of bitter orange juice. In addition, Robbins [43] found that phenolic acids (caffeic, $p$-coumaric, ferulic, and sinapic) are characteristic of Citrus. Furthermore, Caro et al. [48] and Gorinstein et al. [49] mentioned that in addition to vitamin $\mathrm{C}$ and carotenoids, a variety of phenolic compounds, namely, flavanone glycosides, and hydroxycinnamic acids, are present 


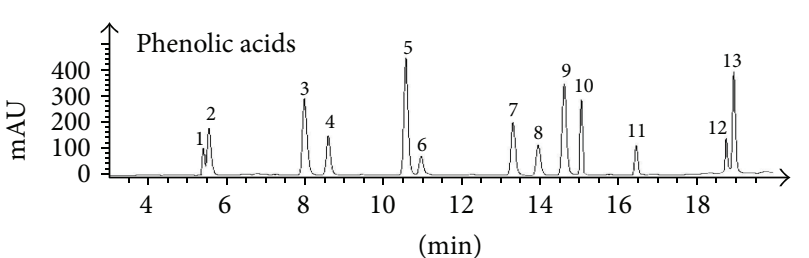

(a)

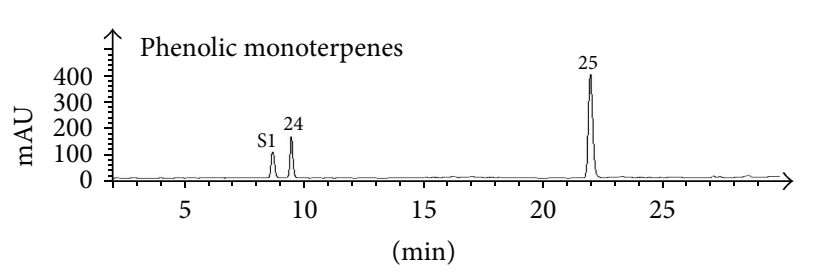

(c)

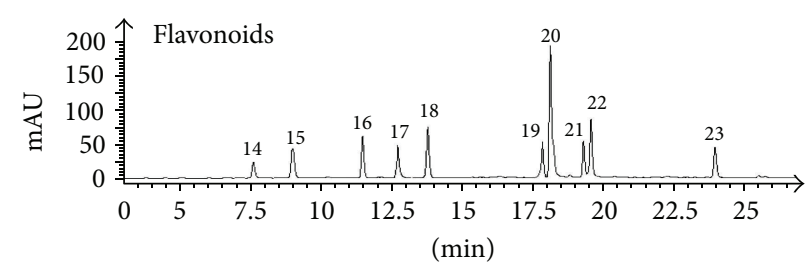

(b)

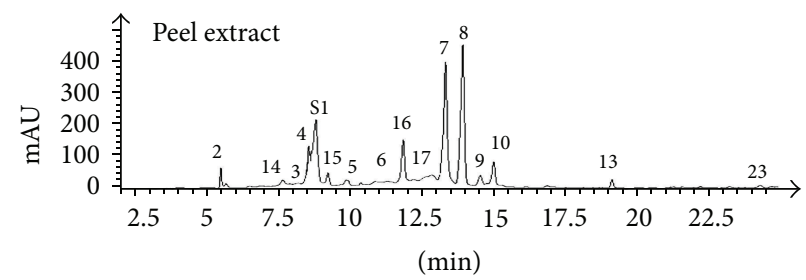

(d)

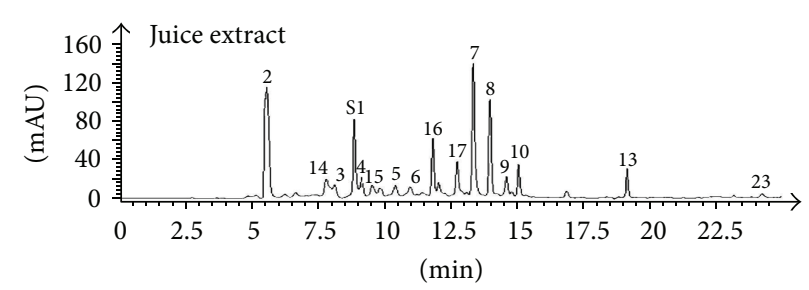

(e)

FIGURE 1: RP-HPLC chromatographic profiles of phenolic acids, flavonoids, and phenolic monoterpenes standards and Citrus aurantium peel and juice extracts monitored at $280 \mathrm{~nm}$. ${ }^{*}$ The peak numbers correspond to the following: 1 . caffeic acid; 2. gallic acid; 3. $p$-hydroxybenzoic acid; 4. chlorogenic acid; 5 . syringic acid; 6 . vanillic acid; 7. p-coumaric acid; 8. ferulic acid; 9. trans-2-hydroxycinnamic acid; 10 . rosmarinic acid; 11. o-coumaric acid; 12. cinnamic acid; 13. trans-cinnamic acid; 14. epicatechin gallate; 15 . catechin; 16 . rutin; 17 . naringin; 18 . quercetrin; 19. luteolin; 20. quercetin; 21. apigenin; 22. amentoflavone; 23. flavone; 24. tyrosol; 25. thymol; S1. resorcinol.

in Citrus fruit as bioactive compounds. Naringin and hesperidin, so-called Citrus flavonoids, are two major flavanone glycosides present in Citrus fruits [48, 50]. All flavonoids described in Citrus sp. can be classified into these groups: flavanones, flavones, and flavonols, and species are characterized by a particular flavanone glycoside pattern. In fact, Citrus plants contain a wide range of flavonoid constituents, some of which are characteristic of them [51]. It is important to note that the Citrus flavonoids have been found to have healthrelated properties, which include anticancer, antiviral, and anti-inflammatory activities, effects on capillary fragility, and an ability to inhibit human platelet aggregation $[52,53]$.

Several studies showed that phenolics exhibit a wide range of biological effects including antibacterial, antiinflammatory, antiallergic, hepatoprotective, antithrombotic, antiviral, anticarcinogenic, and vasodilatory actions $[54,55]$. For instance, phenol carboxylic acids such as caffeic, chlorogenic, $p$-coumaric, and ferulic acids exert beneficial effects on human health through prevention of degenerative pathologies such as cardiovascular diseases and cancer [56]. Zang et al. [57] showed that $p$-coumaric acid can act as a direct scavenger of reactive oxygen species to prevent lipid peroxidation, reduce serum cholesterol levels, and enhance the resistance of LDL to oxidation. In addition, Srinivasan et al. [58] reported that ferulic acid exhibits a wide range of therapeutic effects against various diseases like cancer, diabetes, cardiovascular, and neurodegenerative diseases. A wide spectrum of beneficial activity for human health has been advocated for this phenolic compound, at least in part, because of its strong antioxidant activity.

3.3. Antioxidant Activities. Considering the multifaceted aspects of antioxidants and their reactivity, several antioxidant assays were applied. In fact, depending on the reaction involved, these assays can roughly be classified into two types: assays based on hydrogen atom transfer reactions and assays based on electron transfer [59]. The result of a single method can give only a reductive view of the antioxidant properties of the extracts [60]. In fact, the antioxidant activity may be due to different mechanisms, such as prevention of chain initiation, decomposition of peroxides, and prevention of continued hydrogen abstraction, free radical scavenging, reducing capacity, and binding of transition metal ion catalysts [61]. Thus, to evaluate antioxidant effectiveness, several analytical methods and different substrates are used.

Total antioxidant capacity by phosphomolybdenum method assay is based on the reduction of $\mathrm{Mo}(\mathrm{VI})$ to $\mathrm{Mo}(\mathrm{V})$ by the sample analyte and the subsequent formation of green phosphate/Mo(V) complex at acidic $\mathrm{pH}$ [3]. The phosphomolybdenum method is quantitative since the total antioxidant activity is expressed as the number of equivalents of gallic acid. The measure of the global antioxidant capacity 
TABLE 2: Contents (mg/g) and percentages (\%) of phenolic compounds of bitter orange peel and juice ${ }^{\mathrm{A}}$.

\begin{tabular}{|c|c|c|c|c|}
\hline \multirow{2}{*}{ Phenolic compounds } & \multicolumn{2}{|c|}{ Peel } & \multicolumn{2}{|c|}{ Juice } \\
\hline & $\%$ & $\mathrm{Mg} / \mathrm{g}$ & $\%$ & $\mathrm{Mg} / \mathrm{L}$ \\
\hline Phenolic acids & $73.80 \pm 3.33^{\mathrm{a}}$ & $1.03 \pm 0.02$ & $71.25 \pm 0.25^{\mathrm{a}}$ & $473.89 \pm 0.30$ \\
\hline Gallic acid & $1.84 \pm 0.25^{\mathrm{b}}$ & $0.03 \pm 0.01$ & $13.05 \pm 0.01^{\mathrm{a}}$ & $84.53 \pm 0.07$ \\
\hline Hydroxybenzoic acid & $1.13 \pm 0.65^{\mathrm{b}}$ & $0.02 \pm 0.01$ & $4.05 \pm 0.11^{\mathrm{a}}$ & $27.88 \pm 0.05$ \\
\hline Chlorogenic acid & $8.63 \pm 0.13^{\mathrm{a}}$ & $0.12 \pm 0.01$ & - & - \\
\hline Syringic acid & $1.69 \pm 0.46^{\mathrm{b}}$ & $0.02 \pm 0.01$ & $2.24 \pm 0.00^{\mathrm{a}}$ & $13.75 \pm 0.1$ \\
\hline Vanillic acid & $1.75 \pm 0.57^{\mathrm{b}}$ & $0.02 \pm 0.01$ & $2.61 \pm 0.04^{\mathrm{a}}$ & $17.19 \pm 0.01$ \\
\hline Rosmarinic acid & $5.58 \pm 0.65^{\mathrm{a}}$ & $0.08 \pm 0.02$ & $5.43 \pm 0.10^{\mathrm{a}}$ & $36.84 \pm 0.02$ \\
\hline Trans-2-hydroxycinnamic acid & $3.15 \pm 0.28^{\mathrm{a}}$ & $0.04 \pm 0.01$ & $4.56 \pm 0.05^{\mathrm{a}}$ & $30.69 \pm 0.20$ \\
\hline Trans-cinnamic acid & $1.56 \pm 0.65^{\mathrm{b}}$ & $0.02 \pm 0.01$ & $2.58 \pm 0.01^{\mathrm{a}}$ & $15.64 \pm 0.09$ \\
\hline$p$-Coumaric acid & $24.68 \pm 2.64^{\mathrm{a}}$ & $0.34 \pm 0.01$ & $18.02 \pm 0.22^{b}$ & $116.13 \pm 0.18$ \\
\hline Ferulic acid & $23.79 \pm 3.27^{\mathrm{a}}$ & $0.33 \pm 0.02$ & $19.04 \pm 0.22^{b}$ & $131.24 \pm 0.21$ \\
\hline Flavonoids & $23.02 \pm 3.83^{\mathrm{a}}$ & $0.33 \pm 0.07$ & $23.13 \pm 1.11^{\mathrm{a}}$ & $136.91 \pm 0.17$ \\
\hline Epicatechin & $2.77 \pm 0.83^{\mathrm{b}}$ & $0.04 \pm 0.02$ & $5.36 \pm 0.15^{\mathrm{a}}$ & $36.47 \pm 0.05$ \\
\hline Catechin & $3.17 \pm 0.27^{\mathrm{a}}$ & $0.04 \pm 0.01$ & $3.16 \pm 0.08^{\mathrm{a}}$ & $20.24 \pm 0.09$ \\
\hline Rutin & $9.91 \pm 1.18^{\mathrm{a}}$ & $0.14 \pm 0.03$ & $5.98 \pm 0.19^{\mathrm{b}}$ & $37.21 \pm 0.10$ \\
\hline Naringin & $5.23 \pm 1.15^{\mathrm{a}}$ & $0.07 \pm 0.02$ & $5.59 \pm 0.04^{\mathrm{a}}$ & $35.05 \pm 0.12$ \\
\hline Flavone & $1.95 \pm 1.98^{\mathrm{a}}$ & $0.03 \pm 0.03$ & $1.19 \pm 0.01^{\mathrm{a}}$ & $7.96 \pm 0.01$ \\
\hline Phenolic monoterpenes & - & & $3.51 \pm 0.17^{\mathrm{a}}$ & $23.54 \pm 0.03$ \\
\hline Tyrosol & - & & $3.51 \pm 0.17^{\mathrm{a}}$ & $23.54 \pm 0.03$ \\
\hline Unknown & $3.18 \pm 0.50$ & $0.04 \pm 0.01$ & 3.62 & $22.79 \pm 0.08$ \\
\hline Total & 100 & $1.40 \pm 0.09$ & 100 & $657.13 \pm 0.27$ \\
\hline
\end{tabular}

TABLE 3: Antioxidant activities of bitter orange peel and juice methanolic extracts ${ }^{\mathrm{A}}$.

\begin{tabular}{lcccc}
\hline & $\begin{array}{c}\text { Total antioxidant capacity } \\
\text { (mg GAE/g FW: peel) } \\
\text { (mg GAE/L: juice) }\end{array}$ & $\begin{array}{c}\mathrm{DPPH} \\
\left(\mathrm{IC}_{50}, \mu \mathrm{g} \mathrm{mL} \mathrm{mL}^{-1} \text { peel }\right) \\
(\% \mathrm{I}: \text { juice })\end{array}$ & $\begin{array}{c}\beta \text {-Carotene bleaching } \\
\left(\mathrm{IC}_{50}, \mathrm{mg} \mathrm{mL}^{-1}: \text { peel }\right) \\
(\% \mathrm{I}: \text { juice })\end{array}$ & $\begin{array}{c}\text { Reducing power } \\
\left(\mathrm{EC}_{50}, \mathrm{mg} \mathrm{mL}^{-1}: \text { peel }\right)\end{array}$ \\
\hline Peel & $5.23 \pm 0.05$ & $190 \pm 0.01$ & $5.81 \pm 0.03$ & $1.88 \pm 0.05$ \\
Juice & $823.13 \pm 17.18$ & $97.05 \pm 0.38$ & $15.92 \pm 0.66$ & - \\
\hline
\end{tabular}

${ }^{\mathrm{A}}$ Values are given as mean $\pm \mathrm{SD}(n=3)$. - : not detected.

considers the cumulative action of all the antioxidants present in plant extract, thus providing an integrated parameter rather than the simple sum of measurable antioxidants. The total antioxidant capacity of plant extracts takes into account all antioxidants and synergistic effects between them. In addition, the antioxidant capacity of phenolic compounds is mainly due to their redox properties, which can play an important role in absorbing and neutralizing free radicals, quenching singlet and triplet oxygen, or decomposing peroxides [62].

Total antioxidant capacities of bitter orange peel and juice methanolic extracts were presented in Table 3. Our study revealed a total antioxidant capacity of $5.23 \mathrm{mg} \mathrm{GAE} / \mathrm{g}$ in the peel extract and $823.13 \mathrm{mg} \mathrm{GAE} / \mathrm{L}$ in the juice. To the best of our knowledge, there are no data concerning bitter orange peel and juice total antioxidant capacities using phosphomolybdenum method. The results of the statistical analysis showed a highly significant positive correlation between total antioxidant activity and flavonoid content of the peel and juice methanolic extracts $(r=0.99, r=-0.98$ at $P<0.05$, resp.).

A similar correlation $(r=0.82, P<0.05)$ was observed by Abeysinghe et al. [47] in four species of Citrus which confirms the close relationship between the antioxidant activity and total flavonoid contents. Our results are also in agreement with those reported by Patil et al. [63] who showed that the antioxidant activity of Citrus aurantifolia juice is due to the presence of flavonoids, phenolic compounds, and ascorbic acid. Peel and juice antioxidant activity might be attributed to the presence of phytochemicals such as phenolic compounds. In fact, several studies [11, 64] attributed antioxidant activities to the presence of phenolic compounds in Citrus. Thus, Citrus fruits have received much attention because of their nutritional and antioxidant properties, and nowadays prevention of health problems through nutrition is promoted intensively [46], due mainly to the contribution of antioxidant compounds including vitamin $\mathrm{C}$, phenolic compounds, and carotenoids. Cano et al. [65] mentioned that 
in Citrus, the major part of the total antioxidant activity is due to the hydrophiliccompound, and some authors have stressed the main role of hesperidin in the total antioxidant capacity of orange juices [66]. Moreover, Citrus species of various origins have been assessed for their phenolic constituents and antioxidant activities [46]. Indeed, Citrus fruit extracts and Citrus flavonoids exhibit a wide range of promising biological properties including antiatherogenic, anti-inflammatory, antitumor activities, and strong antioxidant capacity [67]. Previous studies have also shown that Citrus fruits are rich in phenolic compounds and have high antioxidant activity [64, 68].

Furthermore, Singh et al. [69] reported that monoterpenic essential oils are considered as natural antioxidants. Similarly, Zia-ur-Rehman [70] found that Citrus fruit byproducts could be interesting not only for their important fibre content but also because of their antioxidant capacity. They have high fibre and vitamin contents as well as other associated bioactive compounds such as flavonoids and terpenes which exhibit interesting antioxidant properties [71].

DPPH can be used to determine the free radical scavenging activity as it forms a stable molecule on accepting an electron or hydrogen atom [72]. There was a reduction in the concentration of DPPH due to the scavenging effect of extracts. The extracts and standard antioxidants reduced $\mathrm{DPPH}$ to yellow coloured product in a concentrationdependent manner.

Free radical scavenging properties of methanolic extract of bitter orange peel and juice are presented in Table 3. Peel methanolic extract showed higher IC $_{50}$ value $(190 \mu \mathrm{g} / \mathrm{mL})$ than that of the standard antioxidant BHT $\left(\mathrm{IC}_{50}=25 \mu \mathrm{g} / \mathrm{mL}\right)$ indicating a low antioxidant capacity strongly correlated with the TF content $(r=0.99, P<0.05)$. Tumbas et al. [73] reported a comparable radical scavenging activity $\left(\mathrm{IC}_{50}=\right.$ $179 \mu \mathrm{g} / \mathrm{mL}$ ) when studying the peel extract of mandarin (Citrus reticulata). However, Ghasemi et al. [20] reported that the Citrus aurantium fruits peel collected in Iran was characterized by a lower antiradical activity $\left(\mathrm{IC}_{50}=1.9 \mathrm{mg} / \mathrm{mL}\right)$. In addition, Muthiah et al. [74] showed that Indian Citrus aurantium peel was characterized by a higher antiradical activity $\left(\mathrm{IC}_{50}=86.83 \mu \mathrm{g} / \mathrm{mL}\right)$. Moreover, Ersus and Cam [11] reported that Turkish sour orange peel-free has higher antiradical activity $\left(\mathrm{IC}_{50}=0.993 \mathrm{mg} / \mathrm{mg}\right)$.

On the other hand, juice methanolic extract was characterized by inhibition percentages of $97.05 \%$. Our results are comparable to those of Tounsi et al. [31] who showed in their study on the antioxidant activity of the juice of four Citrus varieties that bitter orange juice has a high antiradical activity compared to blood orange, lemon, and mandarin $(96.1 \%$, $90.21 \%, 63.8 \%$, and $56.75 \%$, resp.). In addition, Patil et al. [63] reported a comparable radical scavenging activity (85.4 and $90 \%$ ) in the chloroform extract of Citrus aurantifolia juice. The statistical analysis shows a highly significant correlation between antiradical activity and TP content of juice extract $(r$ $=-0.99, P<0.05)$. These results are similar to those of Amić et al. [75] who reported a correlation between the phenolic content and antioxidant capacity of plant foods. According to Rangkadilok et al. [76] and Patil et al. [63], the antiradical activity of peel, juice, and pulp is partly attributed to phenolic compounds such as gallic acid and rutin which have high antiradical activity.

In addition, according to Kumaran and Joel Karunakaran [77], antioxidant molecules such as polyphenols, flavonoids, and tannins reduce and discolour DPPH due to their hydrogen donating ability. Moreover, Tounsi et al. [31] mentioned that bitter orange and blood orange juices displayed higher activity than lemon and mandarin (values were $96.1 \%$, $90.21 \%, 63.8 \%$, and $56.75 \%$, resp.).

The free radical scavenging activity of fruit extracts [78] has been extensively studied. Essential oils rich in monoterpenes are recognized as food preservatives, and monoterpenic essential oils are natural antioxidants that are active against certain cancers [79]. Indeed, a number of dietary monoterpenes have antitumoral activity that can prevent the formation or progress of cancer and cause tumor regression. Limonene has a well-established protective activity against many types of cancer [80]. In addition, the phenolic acids exhibited radical scavenging activities in the order of gallic $>$ gentisic $>$ syringic $>$ caffeic $>$ protocatechuic $>$ sinapic $>$ ferulic $>$ isoferulic $>$ vanillic $>p$-coumaric $>o$-coumaric $>m$ coumaric $>$ salicylic $\gg p$-hydroxybenzoic. Gallic acid, with three hydroxyl groups, was observed to be the most active phenolic acid [81].

Ogiwara et al. [82] previously found that caffeic, chlorogenic, and ferulic acids scavenged various radicals such as superoxide anions and hydroxy radicals.

On the other hand, Kanski et al. [83] reported that ferulic acid is a phenolic compound that possesses three distinctive structural motifs that can possibly contribute to the free radical scavenging capability of this compound. The presence of electron donating groups on the benzene ring (3 methoxy and more importantly 4-hydroxyl) of ferulic acid gives the additional property of terminating free radical chain reactions. The next functionality-the carboxylic acid group in ferulic acid with an adjacent unsaturated $\mathrm{C}-\mathrm{C}$ double bond-can provide additional attack sites for free radicals and thus prevent them from attacking the membrane. In addition, this carboxylic acid group also acts as an anchor of ferulic acid, by which it binds to the lipid bilayer, providing some protection against lipid peroxidation [83].

In the $\beta$-carotene linoleate system, $\beta$-carotene undergoes rapid discolouration in the absence of antioxidants. This test measures the sample's potential for inhibiting conjugated diene hydroperoxides formation from linoleic acid oxidation [84].

Our results (Table 3 ) showed that the antioxidant activity of the peel extract was very low $\left(\mathrm{IC}_{50}=5.81 \mathrm{mg} / \mathrm{mL}\right)$ compared to antioxidant standards BHT $\left(\mathrm{IC}_{50}=0070 \mathrm{mg} / \mathrm{mL}\right)$ and BHA $\left(\mathrm{IC}_{50}=0.043 \mathrm{mg} / \mathrm{mL}\right)$. This activity is strongly correlated with the flavonoid content $(r=-0.98, P<0.05)$. The inhibitory effect of $\beta$-carotene by the peel methanolic extracts could be due to polar phenolic compounds such as antioxidants. Indeed, Narayan et al. [85] found that flavonoids can inhibit lipid peroxidation process by scavenging free radicals. To the best of our knowledge, there are no data concerning the $\beta$-carotene bleaching inhibition capacity of bitter orange peel extract. 
The results in Table 3 proved that the juice extract was characterized by a low antioxidant activity of $15.92 \%$. After statistical analysis, our results showed a highly significant correlation between this antioxidant capacity and TP content $(r=-0.98, P<0.05)$. Similar results were found by Tounsi et al. [31] indicating a low antioxidant activity (18.27\%) of bitter orange juice compared to lemon $(22.67 \%)$ and mandarin (26.67\%) juices.

The transformation of $\mathrm{Fe}^{3+}$ into $\mathrm{Fe}^{2+}$ in the presence of various fractions was measured to determine the reducing power ability. The reducing ability of a compound generally depends on the presence of reductones (antioxidants), which exert the antioxidant activity by breaking the free radical chain by donating a hydrogen atom [86]. The reduction of the $\mathrm{Fe}^{3+}$ /ferricyanide complex to the ferrous form occurs due to the presence of reductants in the solution [87]. Reductones are believed not only to react directly with peroxides but also prevent peroxide formation by reacting with certain precursors. According to Amarowicz et al. [88], reducing power is associated with the antioxidant activity.

Table 3 showed that bitter orange peel methanolic extract exhibited a very little $\mathrm{Fe}^{3+}$ reducing power ability since its $\mathrm{EC}_{50}$ value $(1.88 \mathrm{mg} / \mathrm{mL})$ was far higher than that of ascorbic acid $(0.04 \mathrm{mg} / \mathrm{mL})$. However, juice's extract showed no reducing power activity. A highly significant correlation was found between the reducing activity and flavonoid or TP contents ( $r=0.91$ and $r=-0.74$, resp., at $P<0.05)$. Different results were reported by $\mathrm{Su}$ et al. [68] who showed greater activity in sour orange peel grown in China $\left(\mathrm{EC}_{50}=0.12 \mathrm{mg} / \mathrm{mL}\right)$. In addition, Muthiah et al. [74] found that Indian Citrus aurantium peel and fruit extracts were characterized by a higher reducing power ability of 0.536 and $0.314 \mu \mathrm{g} / \mathrm{mL}$ at the highest concentration tested $(800 \mu \mathrm{g} / \mathrm{mL})$. However, our results were in agreement with those of Ramful et al. [89] who found that TP of the flavedo extract of Citrus fruits grown in Mauritius correlated strongly with ferric reducing antioxidant capacity $(r=0.88)$. The antioxidant activity of peel extract might be due to the reduction of superoxide anion, inactivation of free radicals, or complexion with metal ions or their combination.

In conclusion, our results showed that Citrus aurantium essential oil was rich in limonene and that ferulic and $p$ coumaric acids were the main phenolic compounds of the peel and juice methanolic extracts. Moreover, our study can be considered as the first report on the antioxidant capacities based on total antioxidant capacity assay, quantification of polyphenols, and HPLC analysis of phenolics. Citrus aurantium peel and juice antioxidant activity was high enough for the plant to be used as a potential resource of natural antioxidants for the food industry so that it is interesting to examine its application as a natural antioxidant additive in some final food products. To understand the antioxidant mechanism of action as bioactive components, further fractionation of methanolic extracts, isolation of phenolic compounds, and determination of their biological activities in vitro and in vivo are needed.

\section{Conflict of Interests}

The authors declare that there is no conflict of interests.

\section{References}

[1] A. Kumaran and R. Joel Karunakaran, "Antioxidant and free radical scavenging activity of an aqueous extract of Coleus aromaticus," Food Chemistry, vol. 97, no. 1, pp. 109-114, 2006.

[2] H. P. Wichi, "Enhanced tumour development by butylated hydroxyanisole (BHA) from the prospective of effect on forestomach and oesophageal squamous epithelium," Food and Chemical Toxicology, vol. 26, pp. 717-723, 1988.

[3] C. K. Ramesh, K. L. Raghu, and K. S. Jamuna, "Govinden Soulange Joyce and Ranghoo-Sanmukhiya Vijayanti Mala and Vijay Avin BR. Comparative evaluation of antioxidant property in methanol extracts of some common vegetables of India," Annals of Biological Research, vol. 2, no. 2, pp. 86-94, 2011.

[4] S. Bourgou, R. Ksouri, A. Bellila, I. Skandrani, H. Falleh, and B. Marzouk, "Phenolic composition and biological activities of Tunisian Nigella sativa L. shoots and roots," Comptes Rendus, vol. 331, no. 1, pp. 48-55, 2008.

[5] I. Jabri-Karoui, I. Bettaieb, K. Msaada, M. Hammami, and B. Marzouk, "Research on the phenolic compounds and antioxidant activities of Tunisian Thymus capitatus," Journal of Functional Foods, vol. 4, no. 3, pp. 661-669, 2012.

[6] F. R. Marín, C. Soler-Rivas, O. Benavente-García, J. Castillo, and J. A. Pérez-Alvarez, "By-products from different citrus processes as a source of customized functional fibres," Food Chemistry, vol. 100, no. 2, pp. 736-741, 2007.

[7] K. Fisher and C. Phillips, "Potential antimicrobial uses of essential oils in food: is citrus the answer?" Trends in Food Science and Technology, vol. 19, no. 3, pp. 156-164, 2008.

[8] B. Steuer, H. Schulz, and E. Läger, "Classification and analysis of citrus oils by NIR spectroscopy," Food Chemistry, vol. 72, no. 1, pp. 113-117, 2001.

[9] H. Nguyen, E. M. Campi, W. Roy Jackson, and A. F. Patti, "Effect of oxidative deterioration on flavour and aroma components of lemon oil," Food Chemistry, vol. 112, no. 2, pp. 388-393, 2009.

[10] I. J. Karoui, W. A. Wannes, and B. Marzouk, "Refined corn oil aromatization by Citrus aurantium peel essential oil," Industrial Crops and Products, vol. 32, no. 3, pp. 202-207, 2010.

[11] S. Ersus and M. Cam, "Determination of organic acids, total phenolic content, and antioxidant capacity of sour Citrus aurantium fruits," Chemistry of Natural Compounds, vol. 43, no. 5, pp. 607-609, 2007.

[12] K. J. Joshipura, F. B. Hu, J. E. Manson et al., "The effect of fruit and vegetable intake on risk for coronary heart disease," Annals of Internal Medicine, vol. 134, no. 12, pp. 1106-1114, 2001.

[13] P. Knekt, J. Kumpulainen, R. Järvinen et al., "Flavonoid intake and risk of chronic diseases," American Journal of Clinical Nutrition, vol. 76, no. 3, pp. 560-568, 2002.

[14] E. J. Middleton and C. Kandaswami, "Potential healthpromoting properties of citrus flavonoids," Food Technology, vol. 48, no. 11, pp. 115-120, 1994.

[15] S. A. Ross, D. S. Ziska, K. Zhao, and M. A. Elsohly, "Variance of common flavonoids by brand of grapefruit juice," Fitoterapia, vol. 71, no. 2, pp. 154-161, 2000.

[16] W. J. Craig, "Phytochemicals: guardians of our health," Journal of the American Dietetic Association, vol. 97, no. 10, pp. S199204, 1997. 
[17] H. Chapot and J. C. Praloran, "Les graines de citrus," in XIV Congrès International Horticole, vol. 2, pp. 1294-1323, 1955.

[18] D. Tønder, M. A. Petersen, L. Poll, and C. E. Olsen, "Discrimination between freshly made and stored reconstituted orange juice using GC Odour Profiling and aroma values," Food Chemistry, vol. 61, no. 1-2, pp. 223-229, 1998.

[19] R. P. Adams, Identification of Essential Oil Components by Gas Chromatography, Quadrupole Mass Spectroscopy Allured, Carol Stream, Ill, USA, 2001.

[20] K. Ghasemi, Y. Ghasemi, and M. A. Ebrahimzadeh, "Antioxidant activity, phenol and flavonoid contents of 13 citrus species peels and tissues," Pakistan Journal of Pharmaceutical Sciences, vol. 22, no. 3, pp. 277-281, 2009.

[21] J.-L. Mau, G.-R. Chao, and K.-T. Wu, "Antioxidant properties of methanolic extracts from several ear mushrooms," Journal of Agricultural and Food Chemistry, vol. 49, no. 11, pp. 5461-5467, 2001.

[22] G. Xu, D. Liu, J. Chen, X. Ye, Y. Ma, and J. Shi, "Juice components and antioxidant capacity of citrus varieties cultivated in China," Food Chemistry, vol. 106, no. 2, pp. 545-551, 2008.

[23] S. Bourgou, R. Ksouri, A. Bellila, I. Skandrani, H. Falleh, and B. Marzouk, "Phenolic composition and biological activities of Tunisian Nigella sativa L. shoots and roots," Comptes Rendus, vol. 331, no. 1, pp. 48-55, 2008.

[24] P. Prieto, M. Pineda, and M. Aguilar, "Spectrophotometric quantitation of antioxidant capacity through the formation of a phosphomolybdenum complex: specific application to the determination of vitamin E," Analytical Biochemistry, vol. 269, no. 2, pp. 337-341, 1999.

[25] T. Hatano, H. Kagawa, T. Yasuhara, and T. Okuda, "Two new flavonoids and other constituents in licorice root: their relative astringency and radical scavenging effects," Chemical and Pharmaceutical Bulletin, vol. 36, no. 6, pp. 2090-2097, 1988.

[26] Y. Zou, Y. Lu, and D. Wei, "Antioxidant activity of a flavonoidrich extract of Hypericum perforatum L. in vitro," Journal of Agricultural and Food Chemistry, vol. 52, no. 16, pp. 5032-5039, 2004.

[27] M. Oyaizu, "Studies on products of the browning reaction prepared from glucose amine," Japanese Journal of Nutrition, vol. 44, pp. 307-315, 1986.

[28] I. I. Koleva, T. A. Van Beek, J. P. H. Linssen, A. De Groot, and L. N. Evstatieva, "Screening of plant extracts for antioxidant activity: a comparative study on three testing methods," Phytochemical Analysis, vol. 13, no. 1, pp. 8-17, 2002.

[29] Statsoft. STATISTICA for Windows (Computer Program Electronic Manual) StatSoft, Tulsa, Okla, USA, 1998.

[30] S. Moufida and B. Marzouk, "Biochemical characterization of blood orange, sweet orange, lemon, bergamot and bitter orange," Phytochemistry, vol. 62, no. 8, pp. 1283-1289, 2003.

[31] M. S. Tounsi, W. A. Wannes, I. Ouerghemmi et al., "Juice components and antioxidant capacity of four Tunisian Citrus varieties," Journal of the Science of Food and Agriculture, vol. 91, no. 1, pp. 142-151, 2011.

[32] K. Hosni, N. Zahed, R. Chrif et al., "Composition of peel essential oils from four selected Tunisian Citrus species: evidence for the genotypic influence," Food Chemistry, vol. 123, no. 4, pp. 1098-1104, 2010.

[33] O. Boussaada and R. Chemli, "Seasonal variation of essential oil composition of Citrus aurantium L. van amara," Journal of Essential Oil-Bearing Plants, vol. 10, no. 2, pp. 109-120, 2007.
[34] D. R. L. Caccioni, M. Guizzardi, D. M. Biondi, A. Renda, and G. Ruberto, "Relationship between volatile components of citrus fruit essential oils and antimicrobial action on Penicillium digitatum and Penicillium italicum," International Journal of Food Microbiology, vol. 43, no. 1-2, pp. 73-79, 1998.

[35] T. M. Moraes, H. Kushima, F. C. Moleiro et al., "Effects of limonene and essential oil from Citrus aurantium on gastric mucosa: role of prostaglandins and gastric mucus secretion," ChemicoBiological Interactions, vol. 180, no. 3, pp. 499-505, 2009.

[36] G. Dugo, A. Verzera, I. Stagno D’Alcontres, A. Cotroneo, and R. Ficarra, "On the genuineness of Citrus essential oil Part XLI. Italian bitter orange essential oil: composition and detection of contamination and additions of oils and terpenes of sweet orange and of lemon," Flavour and Fragrance Journal, vol. 8, no. 1, pp. 25-33, 1993.

[37] P. P. Mouly, C. R. Arzouyan, E. M. Gaydou, and J. M. Estienne, "Differentiation of citrus juices by factorial discriminant analysis using liquid chromatography of flavanone glycosides," Journal of Agricultural and Food Chemistry, vol. 42, no. 1, pp. 70-79, 1994.

[38] J. Sun, "D-limonene: safety and clinical applications," Alternative Medicine Review, vol. 12, no. 3, pp. 259-264, 2007.

[39] J. S. Baik, S.-S. Kim, J.-A. Lee et al., "Chemical composition and biological activities of essential oils extracted from Korea endemic citrus species," Journal of Microbiology and Biotechnology, vol. 18, no. 1, pp. 74-79, 2008.

[40] M. F. Agra, K. N. Silva, I. J. L. Basílio D, P. F. França, and J. M. Barbosa-Filho, "Survey of medicinal plants used in the region Northeast of Brazil," Revista Brasileira de Farmacognosia, vol. 18, pp. 472-508, 2008.

[41] M. I. R. Carvalho-Freitas and M. Costa, "Anxiolytic and sedative effects of extracts and essential oil from Citrus aurantium L," Biological and Pharmaceutical Bulletin, vol. 25, no. 12, pp. 1629$1633,2002$.

[42] A. Bocco, M.-E. Cuvelier, H. Richard, and C. Berset, "Antioxidant activity and phenolic composition of citrus peel and seed extracts," Journal of Agricultural and Food Chemistry, vol. 46, no. 6, pp. 2123-2129, 1998.

[43] R. J. Robbins, "Phenolic acids in foods: an overview of analytical methodology," Journal of Agricultural and Food Chemistry, vol. 51, no. 10, pp. 2866-2887, 2003.

[44] S. Gorinstein, O. Martín-Belloso, Y.-S. Park et al., "Comparison of some biochemical characteristics of different citrus fruits," Food Chemistry, vol. 74, no. 3, pp. 309-315, 2001.

[45] B. Alexandra, C. Marie Elisabeth, R. Hubert, and B. Clendette, "Antioxidant activity and phenolic composition of citrus peel and seed extracts," Journal of Agricultural and Food Chemistry, vol. 46, no. 6, pp. 2123-2129, 1998.

[46] M. A. Anagnostopoulou, P. Kefalas, V. P. Papageorgiou, A. N. Assimopoulou, and D. Boskou, "Radical scavenging activity of various extracts and fractions of sweet orange peel (Citrus sinensis)," Food Chemistry, vol. 94, no. 1, pp. 19-25, 2006.

[47] D. C. Abeysinghe, X. Li, C. Sun, W. Zhang, C. Zhou, and K. Chen, "Bioactive compounds and antioxidant capacities in different edible tissues of citrus fruit of four species," Food Chemistry, vol. 104, no. 4, pp. 1338-1344, 2007.

[48] A. D. Caro, A. Piga, V. Vacca, and M. Agabbio, "Changes of flavonoids, vitamin $\mathrm{C}$ and antioxidant capacity in minimally processed citrus segments and juices during storage," Food Chemistry, vol. 84, no. 1, pp. 99-105, 2004.

[49] S. Gorinstein, R. Haruenkit, Y.-S. Park et al., "Bioactive compounds and antioxidant potential in fresh and dried Jaffa $®$ 
sweeties, a new kind of citrus fruit," Journal of the Science of Food and Agriculture, vol. 84, no. 12, pp. 1459-1463, 2004.

[50] F. I. Kanaze, C. Gabrieli, E. Kokkalou, M. Georgarakis, and I. Niopas, "Simultaneous reversed-phase high-performance liquid chromatographic method for the determination of diosmin, hesperidin and naringin in different citrus fruit juices and pharmaceutical formulations," Journal of Pharmaceutical and Biomedical Analysis, vol. 33, no. 2, pp. 243-249, 2003.

[51] Y. Nogata, K. Sakamoto, H. Shiratsuchi, T. Ishii, M. Yano, and H. Ohta, "Flavonoid composition of fruit tissues of citrus species," Bioscience, Biotechnology and Biochemistry, vol. 70, no. 1, pp. 178-192, 2006.

[52] R. Huet, "Constituants des agrumes a effet pharmacodynamique: les citroflavonoides (Constituents of citrus fruits with pharmacodynamic effect: citroflavonoids)," Fruits, vol. 37, pp. 267-271, 1982.

[53] O. Benavente-Garcia, J. Castillo, F. R. Marin, A. Ortuno, and J. A. Del Rio, "Uses and properties of Citrus flavonoids," Journal of Agricultural and Food Chemistry, vol. 45, pp. 4505-4515, 1997.

[54] J. C. Espin, M. T. Garcia-Conesa, and F. A. Tomas-Barberan, "Nutraceuricals: facts and fiction," Phytochem, vol. 68, pp. 29863008, 2007.

[55] E. Middleton Jr., C. Kandaswami, and T. C. Theoharides, “The effects of plant flavonoids on mammalian cells: implications for inflammation, heart disease, and cancer," Pharmacological Reviews, vol. 52, no. 4, pp. 673-751, 2000.

[56] A. Bendini, L. Cerretani, A. Carrasco-Pancorbo et al., "Phenolic molecules in virgin olive oils: a survey of their sensory properties, health effects, antioxidant activity and analytical methods. An overview of the last decade," Molecules, vol. 12, no. 8, pp. 1679-1719, 2007.

[57] L.-Y. Zang, G. Cosma, H. Gardner, X. Shi, V. Castranova, and V. Vallyathan, "Effect of antioxidant protection by p-coumaric acid on low-density lipoprotein cholesterol oxidation," American Journal of Physiology, vol. 279, no. 4, pp. C954-C960, 2000.

[58] M. Srinivasan, A. R. Sudheer, and V. P. Menon, "Ferulic acid: therapeutic potential through its antioxidant property," Journal of Clinical Biochemistry and Nutrition, vol. 40, no. 2, pp. 92-100, 2007.

[59] D. Huang, O. U. Boxin, and R. L. Prior, "The chemistry behind antioxidant capacity assays," Journal of Agricultural and Food Chemistry, vol. 53, no. 6, pp. 1841-1856, 2005.

[60] E. A. Hayouni, M. Abedrabba, M. Bouix, and M. Hamdi, "The effects of solvents and extraction method on the phenolic contents and biological activities in vitro of Tunisian Quercus coccifera L. and Juniperus phoenicea L. fruit extracts," Food Chemistry, vol. 105, no. 3, pp. 1126-1134, 2007.

[61] L.-C. Mao, X. Pan, F. Que, and X.-H. Fang, "Antioxidant properties of water and ethanol extracts from hot air-dried and freeze-dried daylily flowers," European Food Research and Technology, vol. 222, no. 3-4, pp. 236-241, 2006.

[62] T. Osawa, "Novel natural antioxidants for utilization in food and biological systems," in Postharvest Biochemistry of Plant Food-Materials in the Tropics, I. Uritani, V. V. Garcia, and E. M. Mendoza, Eds., pp. 241-251, Japan Scientific Societies Press, Tokyo, Japan, 1994.

[63] J. R. Patil, K. N. Chidambara Murthy, G. K. Jayaprakasha, M. B. Chetti, and B. S. Patil, "Bioactive compounds from mexican lime (Citrus aurantifolia) juice induce apoptosis in human pancreatic cells," Journal of Agricultural and Food Chemistry, vol. 57, no. 22, pp. 10933-10942, 2009.
[64] A.-Y. Wang, M.-Y. Zhou, and W.-C. Lin, "Antioxidative and anti-inflammatory properties of Citrus sulcata extracts," Food Chemistry, vol. 124, no. 3, pp. 958-963, 2011.

[65] A. Cano, A. Medina, and A. Bermejo, "Bioactive compounds in different citrus varieties. Discrimination among cultivars," Journal of Food Composition and Analysis, vol. 21, no. 5, pp. 377381, 2008.

[66] C. Dhuique-Mayer, C. Caris-Veyrat, P. Ollitrault, F. Curk, and M.-J. Amiot, "Varietal and interspecific influence on micronutrient contents in citrus from the mediterranean area," Journal of Agricultural and Food Chemistry, vol. 53, no. 6, pp. 2140-2145, 2005.

[67] S. Samman, P. M. L. Wall, and N. C. Cook, "Flavonoids and coronary heart disease: dietary perspectives," in Flavonoids in the Living System, J. A. Manthey and B. S. Buslig, Eds., pp. 469448, Plenum Press, New York, NY, USA, 1996.

[68] M.-S. Su, Y.-T. Shyu, and P.-J. Chien, "Antioxidant activities of citrus herbal product extracts," Food Chemistry, vol. 111, no. 4, pp. 892-896, 2008.

[69] P. Singh, R. Shukla, B. Prakash et al., "Chemical profile, antifungal, antiaflatoxigenic and antioxidant activity of Citrus maxima Burm. and Citrus sinensis (L.) Osbeck essential oils and their cyclic monoterpene, DL-limonene," Food and Chemical Toxicology, vol. 48, no. 6, pp. 1734-1740, 2010.

[70] Z.-U. Zia-ur-Rehman, "Citrus peel extract-a natural source of antioxidant," Food Chemistry, vol. 99, no. 3, pp. 450-454, 2006.

[71] Y. Lario, E. Sendra, J. García-Pérez et al., "Preparation of high dietary fiber powder from lemon juice by-products," Innovative Food Science and Emerging Technologies, vol. 5, no. 1, pp. 113-117, 2004.

[72] M. Jun, U. Tohru, L. J. Zhang, and F. Takeshi, "Identification and evaluation of antioxidant activities of bamboo extracts," Forestry Studies in China, vol. 6, no. 2, pp. 1-5, 2004.

[73] V. T. Tumbas, G. S. Ćetković, S. M. Djilas et al., "Antioxidant activity of mandarin (Citrus reticulata) peel," BIBLID, vol. 40, pp. 195-203, 2010.

[74] P. L. Muthiah, M. Umamaheswari, and K. Asokkumar, "In vitro antioxidant activities of leaves, fruits and peel extracts of Citrus," International Journal of Phytopharmacy, pp. 13-20, 2012.

[75] D. Amić, D. Davidović-Amicć, D. Bexlo, and N. Trinajstić, "Structure-radical scavenging activity relationships of flavonoids," Croatica Chemica Acta, vol. 76, no. 1, pp. 55-61, 2003.

[76] N. Rangkadilok, S. Sitthimonchai, L. Worasuttayangkurn, C. Mahidol, M. Ruchirawat, and J. Satayavivad, "Evaluation of free radical scavenging and antityrosinase activities of standardized longan fruit extract," Food and Chemical Toxicology, vol. 45, no. 2, pp. 328-336, 2007.

[77] A. Kumaran and R. Joel Karunakaran, "In vitro antioxidant activities of methanol extracts of five Phyllanthus species from India," Food Science and Technology, vol. 40, no. 2, pp. 344-352, 2007.

[78] C. Kaur and H. C. Kapoor, "Antioxidants in fruits and vegetables-the millennium's health," International Journal of Food Science and Technology, vol. 36, no. 7, pp. 703-725, 2001.

[79] M. R. Maróstica Junior, T. A. A. Rocha e Silva, G. C. Franchi, A. Nowill, G. M. Pastore, and S. Hyslop, "Antioxidant potential of aroma compounds obtained by limonene biotransformation of orange essential oil," Food Chemistry, vol. 116, no. 1, pp. 8-12, 2009. 
[80] P. L. Crowell, "Prevention and therapy of cancer by dietary monoterpenes," Journal of Nutrition, vol. 129, no. 3, pp. 77557785, 1999.

[81] M. Karamaæ, A. Kosiñska, and R. B. Pegg, "Comparison of radical-scavenging activities for selected phenolic acids," Polish Journal of Food and Nutrition Sciences, vol. 14, no. 2, pp. 165-170, 2005.

[82] T. Ogiwara, K. Satoh, T. Negoro, H. Okayasu, H. Sakagami, and S. Fujisawa, "Inhibition of NO production by activated macrophages by phenolcarboxylic acid monomers and polymers with radical scavenging activity," Anticancer Research, vol. 23, no. 2 B, pp. 1317-1323, 2003.

[83] J. Kanski, M. Aksenova, A. Stoyanova, and D. A. Butterfield, "Ferulic acid antioxidant protection against hydroxyl and peroxyl radical oxidation in synaptosomal and neuronal cell culture systems in vitro: structure-activity studies," Journal of Nutritional Biochemistry, vol. 13, no. 5, pp. 273-281, 2002.

[84] B. Tepe, M. Sokmen, H. A. Akpulat, D. Daferera, M. Polissiou, and A. Sokmen, "Antioxidative activity of the essential oils of Thymus sipyleus subsp. sipyleus var. sipyleus and Thymus sipyleus subsp. sipyleus var. rosulans," Journal of Food Engineering, vol. 66, no. 4, pp. 447-454, 2005.

[85] M. S. Narayan, K. A. Naidu, G. A. Ravishankar, L. Srinivas, and L. V. Venkataraman, "Antioxidant effect of anthocyanin on enzymatic and non-enzymatic lipid peroxidation," Prostaglandins Leukotrienes and Essential Fatty Acids, vol. 60, no. 1, pp. 1-4, 1999.

[86] S. Meir, J. Kanner, B. Akiri, and S. Philosoph-Hadas, "Determination and involvement of aqueous reducing compounds in oxidative defense systems of various senescing leaves," Journal of Agricultural and Food Chemistry, vol. 43, no. 7, pp. 1813-1819, 1995.

[87] Y.-S. Huang and S.-C. Ho, "Polymethoxy flavones are responsible for the anti-inflammatory activity of citrus fruit peel," Food Chemistry, vol. 119, no. 3, pp. 868-873, 2010.

[88] R. Amarowicz, R. B. Pegg, P. Rahimi-Moghaddam, B. Barl, and J. A. Weil, "Free-radical scavenging capacity and antioxidant activity of selected plant species from the Canadian prairies," Food Chemistry, vol. 84, no. 4, pp. 551-562, 2004.

[89] D. Ramful, T. Bahorun, E. Bourdon, E. Tarnus, and O. I. Aruoma, "Bioactive phenolics and antioxidant propensity of flavedo extracts of Mauritian citrus fruits: potential prophylactic ingredients for functional foods application," Toxicology, vol. 278, no. 1, pp. 75-87, 2010. 

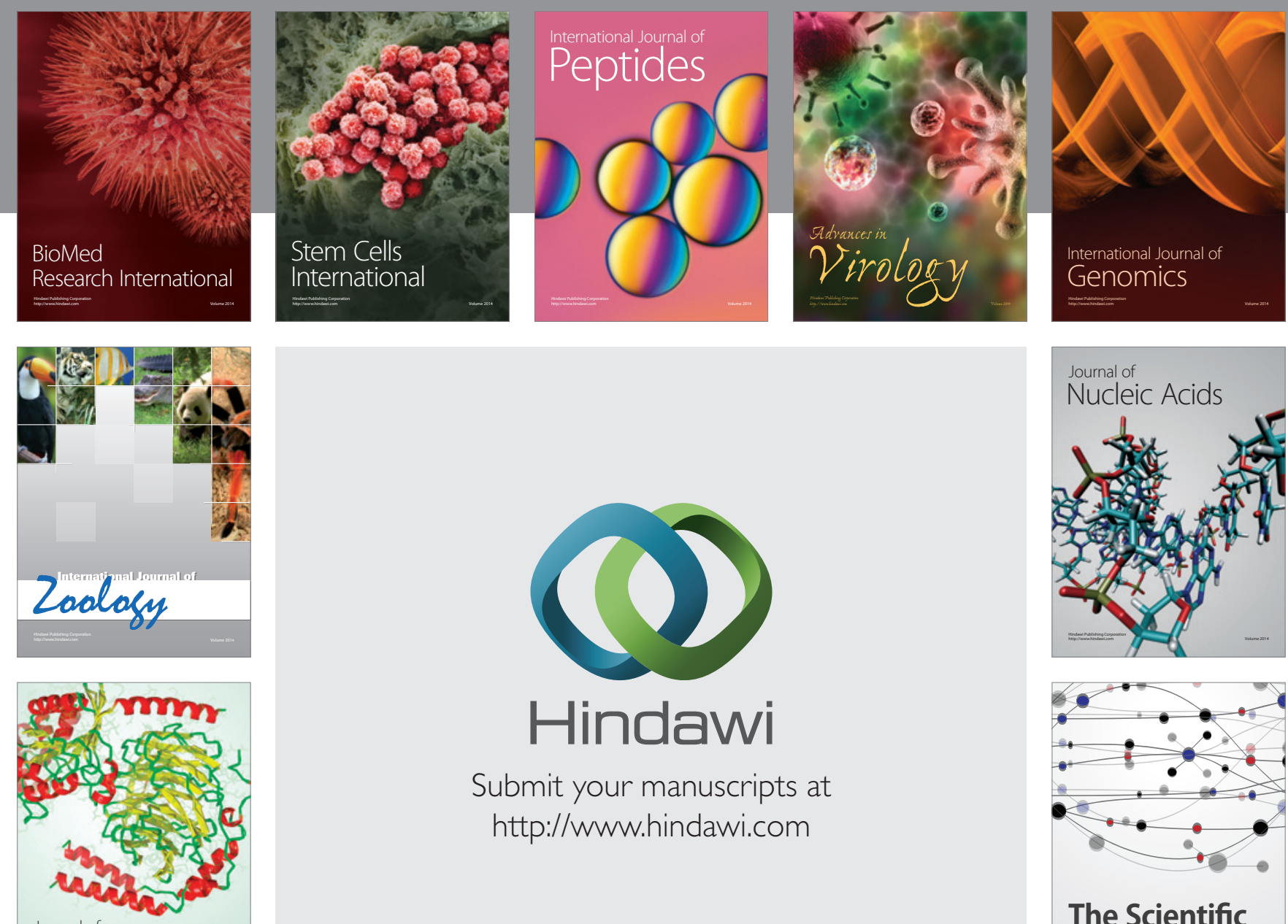

Submit your manuscripts at

http://www.hindawi.com

Journal of
Signal Transduction
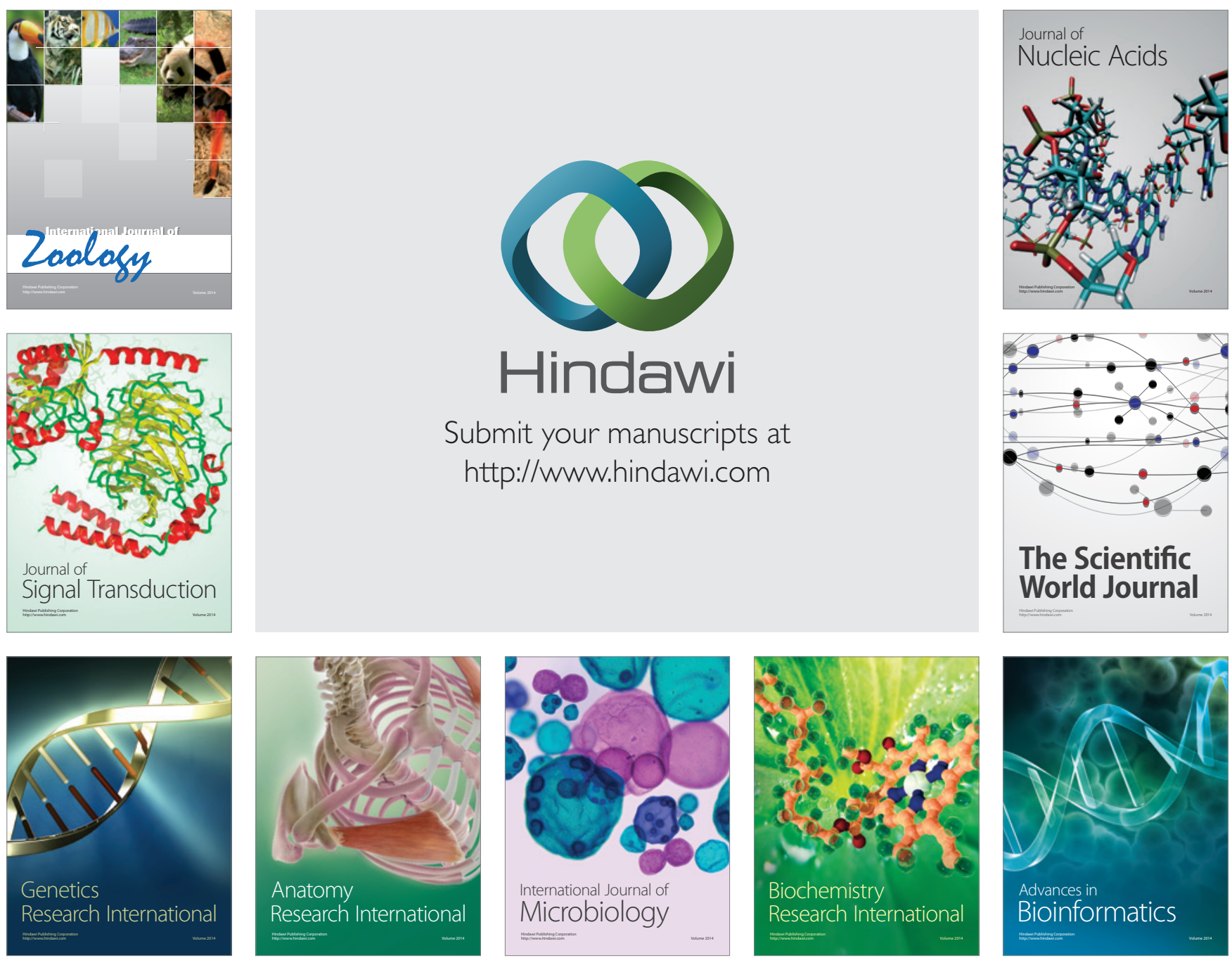

The Scientific World Journal
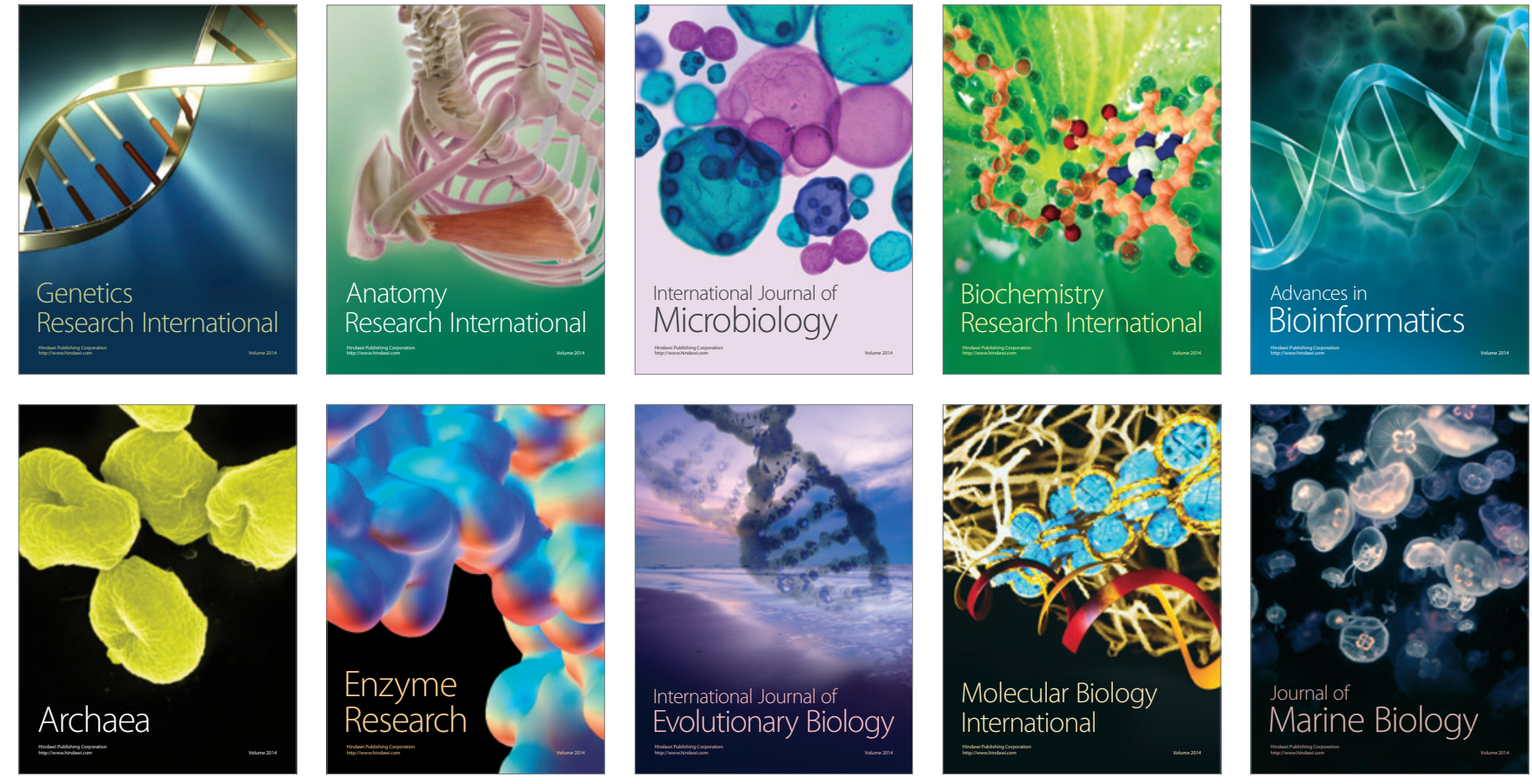